\title{
A Study of $\beta$-Casein Tertiary Structure by Intramolecular Crosslinking and Mass Spectrometry
}

\author{
Y. D. Livney, ${ }^{1}$ A. L. Schwan, ${ }^{2}$ and D. G. Dalgleish ${ }^{1}$ \\ ${ }^{1}$ Department of Food Science and \\ ${ }^{2}$ Department of Chemistry and Biochemistry, \\ University of Guelph, ON, Canada N1G 2W1
}

\section{ABSTRACT}

The objective of this study was to obtain experimental evidence to extend the discussion on the 3 -D structure of $\beta$-casein ( $\beta$-CN). The approach involved the preparation of homobifunctional crosslinkers, bis(sulfosuccinimidyl) derivatives of dicarboxylic acids of several lengths, which specifically react with primary amines of lysinyl residues or the $\mathrm{N}$-terminal in the protein. The intramolecular crosslinks formed were determined by enzymatic digestion and by matrix-assisted laser desorption and ionization time-of-flight mass spectrometry combined with comparison against the theoretical digestion patterns. This procedure allowed the measurement of distances between the crosslinked residues. Ten different masses arising from 8 different specific intramolecular crosslinks were identified. Of these, 5 crosslinks were in good agreement with a published model (Kumosinski et al., 1993). Two other crosslinks each connected 2 residues that are much closer together, according to the model, than the maximum length of the crosslink. However, one of the crosslinks apparently connected 2 residues that are predicted by the model to be $16.7 \AA$ farther apart than the crosslink's stretched length. This disparity might be explained by structural flexibility. The structure expressed by the model is probably one of several energetically favorable conformations of the $\beta$-CN molecule, whose structure is best described as rheomorphic rather than either a fixed structure or a random coil.

(Key words: milk protein, $\beta$-casein, tertiary structure, mass spectrometry)

Abbreviation key: MALDI-TOF MS = matrix-assisted laser desorption and ionization time-of-flight mass spectrometry, $\mathbf{S E C}=$ size exclusion chromatography, $\mathbf{X L}=$ crosslinker.

Received February 25, 2004.

Accepted June 25, 2004.

Corresponding author: D. G. Dalgleish; e-mail: ddalglei@ uoguelph.ca.

\section{INTRODUCTION}

In recent years, a technique for determining structural parameters of proteins has been developed, involving the use of crosslinking agents to study intramolecular distances within the tertiary structure (Young et al., 2000; Sinz, 2003). Specifically, a homobifunctional crosslinker (XL), a bis(sulfosuccinimidyl) derivative of a dicarboxylic acid that specifically reacts with the amine groups of Lys residues or the $\mathrm{N}$-terminal, is reacted with the protein to crosslink pairs of these residues, whose distance apart in the molecular structure is compatible with the length of the crosslinking agent. The intramolecular crossslinks formed are then identified by digestion of the protein with proteolytic enzymes followed by analysis of the proteolytic digest using mass spectrometry. The identification of specific crosslinks allows determination of 3-D distances between the crosslinked residues in the tertiary structure of the protein. This method has been shown to be valid for proteins of fixed structure (Young et al., 2000), but also offers an opportunity to determine at least some structural information for proteins that cannot be crystallized and whose structures are therefore difficult to define. An excellent example of such proteins is bovine $\beta$-CN, which is known not to crystallize (Dalgleish, 1997) nor to belong to any group of homologous crystallizable proteins (Farrell et al., 1990). In addition to the lack of X-ray crystallographic information, it does not appear that the structure of this protein has been analyzed by the alternative technique of nuclear magnetic resonance spectroscopy

$\beta$-Casein constitutes about $38 \%$ of the casein in bovine milk (Swaisgood, 2003). Its primary structure (Ribadeau-Dumas et al., 1972; Swaisgood, 2003; The Swiss Institute of Bioinformatics, 2003) is composed of 209 amino acids, and its molecular mass is 23,946 to 24,097 $\mathrm{Da}$ (depending on the genetic variant). It contains 5 serine-phosphate residues arranged in one phosphate center of 4 Ser-P residues in the region 14 to 21 and an additional single Ser-P in position 35 . Therefore, it is calcium sensitive (DeKruif and Holt, 2003; Swaisgood, 2003). It is claimed to be the most hydrophobic casein 
because of its large hydrophobic C-terminal domain (based on its primary structure). However, its highly charged N-terminal domain, containing the phosphate center, makes it very amphipathic (Swaisgood, 2003). So, it tends to self-aggregate into micelles of 15 to 60 molecules (Schmidt and Payens, 1972) with a radius of gyration of 7.3 to $13.5 \mathrm{~nm}$ (Andrews et al., 1979; Thurn et al., 1987; Kajiwara et al., 1988). Its critical micellization concentration ranges between 0.5 and $2 \mathrm{mg} / \mathrm{mL}$ (Schmidt and Payens, 1972; Niki et al., 1977; Evans et al., 1979) depending on temperature, $\mathrm{pH}$, and ionic strength (Swaisgood, 2003). At low temperatures, the protein is monomeric, with a Stokes radius of $3.7 \mathrm{~nm}$ based on gel chromatography (Schmidt and Payens, 1972), and a radius of gyration of $4.6 \mathrm{~nm}$, based on small-angle X-ray scattering (Schmidt and Payens, 1972; Andrews et al., 1979). From these and other measurements, it has been inferred that it has a somewhat elongated, hydrated ( 6 to $8 \mathrm{~g}$ of $\mathrm{H}_{2} \mathrm{O} / \mathrm{g}$ of protein), flexible structure (Swaisgood, 2003).

The secondary structure reported, as determined by Fourier transform infrared or circular dichroism spectroscopies, constitutes 20 or $29 \% \alpha$-helix, 32 or $34 \% \beta$ structure, 28 or $32 \%$ turns, and 22 or $4 \%$ irregular structure, respectively (Farrell et al., 2001). Kumosinski et al. (1993) developed an ab initio calculated predictive tertiary structure model using molecular modeling techniques, secondary structure prediction, and global secondary structure empirical information from Raman spectroscopy. The model was further refined using a free-energy minimization algorithm. Although it has been claimed that the model explains some of the properties of the protein (Kumosinski et al., 1993), there is still a lack of experimental evidence of the 3$\mathrm{D}$ folding of the protein to allow comparison with the calculated model.

The present study was undertaken to determine the feasibility of using the crosslinking method to study $\beta$ CN tertiary structure and to compare the identified crosslinks with the predicted model.

A homologous series of XL of different lengths was synthesized by using 4 different dicarboxylic acids to prepare the bis(sulfosuccinimidyl) derivatives. These were reacted with $\beta$-CN, and the monomeric reaction products were isolated by size exclusion chromatography (SEC) and digested using 2 proteolytic enzymes, trypsin and Glu-C, which have different and complementary cleavage rules. By combining their results, it was possible to obtain a more comprehensive picture of the crosslinks formed. The peptides produced were analyzed by matrix-assisted laser desorption and ionization time-of-flight mass spectrometry (MALDI-TOF MS), and the distance information results of the crosslinking were compared with the model of Kumosinski et al. (1993) using the published coordinates available from Kumosinski et al. (2003).

\section{MATERIALS AND METHODS}

\section{Principle of the Method}

Figure 1 shows the molecular formula of the homologous series of the XL prepared and describes the crosslinking reaction.

Figure 2 depicts the interaction between the XL and the protein. Only a XL that binds by both ends to a single protein molecule can provide 3 -D information. The doubly reacted XL must not be bound to 2 amino acids that are less than 6 to 8 (depending on XL length) amino acids apart in the sequence (Young et al., 2000).

Tables 1 and 2 summarize the properties of the XL prepared and used in this study. The length from one backbone $\alpha$ carbon to the other was calculated based on standard bond lengths (Chang, 2002) and bond angles, according to the principles outlined by Tanford (1972).

\section{Materials}

HEPES (acid form, 99.5\%), bromophenol blue (reagent grade sodium salt), SDS (99\%), sinapinic acid (98\%), equine cytochrome C (97\%), ACTH clipped 1839 (99\%), $\alpha$-cyano-4-hydroxycinnamic acid, Trizma base (99.9\%), citric acid (anhydrous), N-hydroxymaleimide (97\%), glutaric acid (99\%), adipic acid (99\%), suberic acid (98\%), sebacic acid (99\%), trypsin (EC 3.4.21.4; Sigma T-6567), and Glu-C endoproteinase from Staphylococcus aureus V8 (EC 3.4.21.19; Sigma P6181) were obtained from Sigma-Aldrich Canada Ltd. (Oakville, ON, Canada). Ammonium bicarbonate (certified), EDTA (certified), acetic acid (99.7\%), methanol (HPLC grade), acetonitrile (HPLC grade), trifluoroacetic acid (99.8\%), 2-mercaptoethanol (98\%), sodium hydroxide (certified), and hydrochloric acid (reagent grade) were obtained from Fisher Scientific (Nepean, ON, Canada). Homogeneous gels (20\% acrylamide), buffer strips for PhastSystem electrophoresis, and PhastGel Blue $R$ (Coomassie R 350 stain tablets) were obtained from Amersham Pharmacia Biotech AB (Baie d'Urfé, Quebec, Canada). The XL bis(sulfosuccinimidyl) suberate $\left(\mathrm{BS}^{3}\right)(81.69 \%$ purity) was obtained from Pierce Biotechnology, Inc. (Rockford, IL) and was used during preliminary crosslinking experiments. It was also used as a reference for verifying the identity and comparing the purity of the XL we made, by matching nuclear magnetic resonance chemical shift plots (not shown). For consistency, only results using XL prepared in our laboratories are described in this paper. 


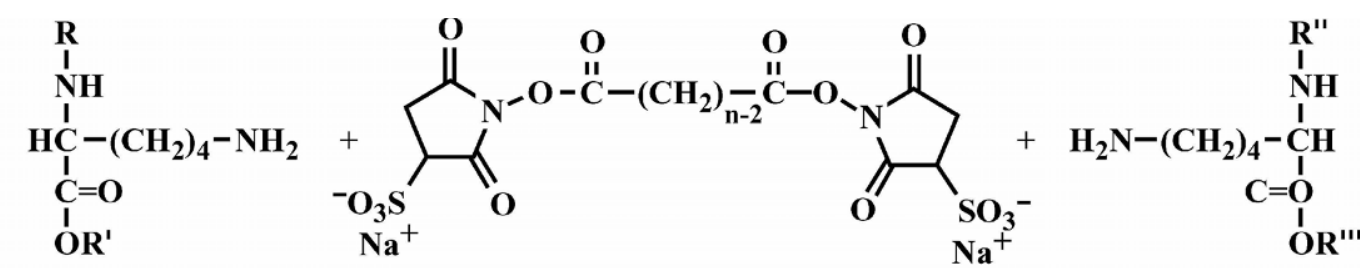

Lysinyl residue

Crosslinked residues:
Bis(sulfosuccinimidyl) derviative of a dicarboxylic acid with $\boldsymbol{n}$ carbons

\section{Lysinyl residue}

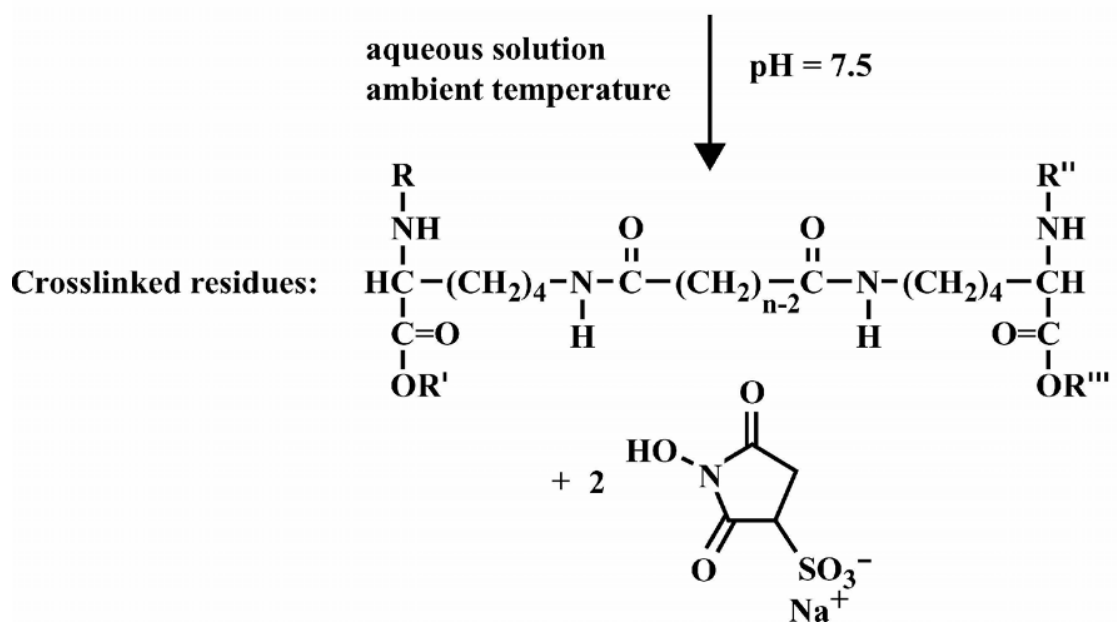

Figure 1. The molecular formula of the homologous series of crosslinkers (XL) and the mechanism of the crosslinking reaction.

\section{Methods}

Protein purification. $\beta$-Casein was isolated from fresh milk by the preparative method described by Dalgleish (1993), which was based on the analytical method of Hollar et al. (1991). The identity and purity (>99\%) of the isolated protein were determined by SDS-PAGE using a PhastSystem (Amersham Pharmacia Biotech $\mathrm{AB})$.

Preparation of $X L$. The XL were synthesized according to a previously described method (Staros, 1982; Scholnick et al., 1992). N-Hydroxymaleimide was recrystallized from toluene before use, and the diacids were used as supplied. Dimethyl formamide was dried by distillation from $\mathrm{P}_{2} \mathrm{O}_{5}$.

Solution preparation and crosslinking reaction conditions. A solution of $0.5 \mathrm{mg} / \mathrm{mL} \beta$-CN dissolved in $20 \mathrm{~m} M$ HEPES-NaOH buffer $(\mathrm{pH}=7.50 \pm 0.01)$ containing $1 \mathrm{~m} M$ EDTA was prepared and stirred for $1 \mathrm{~h}$, refrigerated overnight at $4^{\circ} \mathrm{C}$, and filtered $(0.22 \mu \mathrm{m})$. Each XL was dissolved to a concentration of $42 \mathrm{mM}$ in $5 \mathrm{~m} M$ citrate- $\mathrm{NaOH}$ buffer ( $\mathrm{pH} 5.0$; filtered $0.22 \mu \mathrm{m}$ ). To $1 \mathrm{~mL}$ of $\beta$-CN solution, $10 \mu \mathrm{L}$ of freshly prepared XL solution was added. The solution was briefly vortexed and maintained at room temperature for $30 \mathrm{~min}$; then, $10 \mu \mathrm{L}$ of $1 M$ Tris- $\mathrm{HCl}(\mathrm{pH}=8.0)$ was added to quench the incompletely reacted $\mathrm{XL}$, to eliminate the possibility of forming erroneous crosslinks during subsequent stages of the treatment. A $250-\mu \mathrm{L}$ aliquot of each sample was eluted on a K9/60 SEC column packed with Superdex 75 (Amersham Pharmacia Biotech AB). It was eluted with $5 \mathrm{mM}$ ammonium bicarbonate $(\mathrm{pH}=$ 8 , filtered $0.22 \mu \mathrm{m}$ ) at a flow rate of $0.28 \mathrm{~mL} / \mathrm{min}$. Two aliquots of each duplicate were eluted (4 runs per XL). Three fractions were collected from each run, containing a) dimers (and possibly also trimers, tetramers, etc.), b) mixed dimers and monomers, and c) monomers only. Samples of $0.8 \mathrm{~mL}$ of each fraction were concentrated $(\times 115)$ by Nanosep 10-k Omega centrifugal devices (Pall Life Sciences, Ann Arbor, MI) at $5000 \times g$ and tested by SDS-PAGE for monomer/dimer content. The c-fractions (containing only the monomeric form of the intramolecularly crosslinked $\beta$-CN) from each of 2 similar aliquots were concentrated $(\times 80)$ using the Nanosep 10-k devices at $5000 \times g$, and then one was digested with trypsin, and the other with Glu-C.

Enzymatic digestion. Each enzyme was initially added at 1:20 wt/wt ratio (enzyme to protein) into a sample volume of $20 \mu \mathrm{L}$. Digestions were carried out 


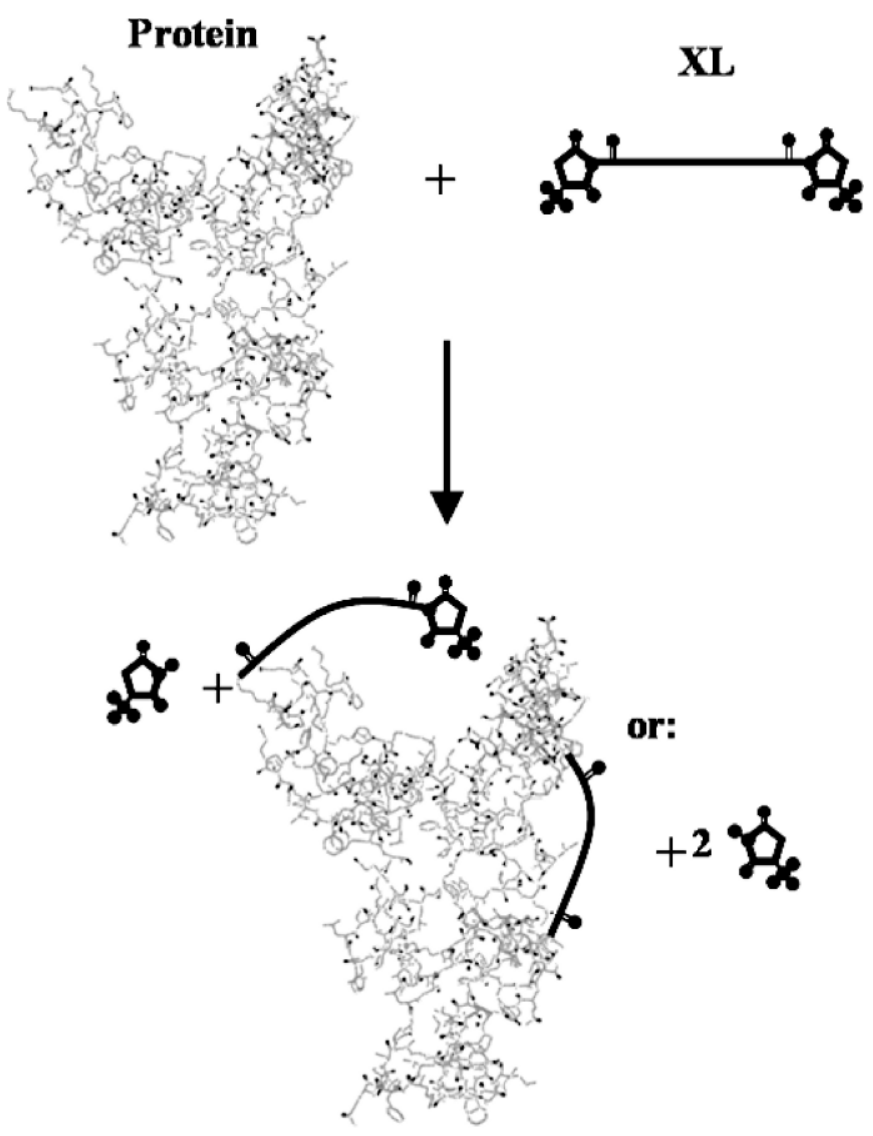

Figure 2. The interaction between the crosslinker (XL) and the protein.

at $37^{\circ} \mathrm{C}$ for $36 \mathrm{~h}$, with the addition of a second aliquot of enzyme after the first $12 \mathrm{~h}$. The digests were then analyzed by MALDI-TOF MS.

MALDI-TOF MS. Matrix-assisted laser desorption and ionization time-of-flight mass spectrometry was used to identify peptides and crosslinked peptides in the protein digests. A $4-\mu \mathrm{L}$ aliquot of each sample of digest was mixed with $4 \mu \mathrm{L}$ of a saturated solution of matrix in $1: 1 \mathrm{H}_{2} \mathrm{O}$ :acetonitrile with $0.1 \%$ trifluoroacetic
Table 2. Details of crosslinkers (XL) used: length.

\begin{tabular}{|c|c|c|}
\hline \multirow[b]{2}{*}{$\begin{array}{l}\text { Number of } \\
\text { carbons } \\
(n) \text { in } \\
\text { bridging } \\
\text { arm }\end{array}$} & \multicolumn{2}{|c|}{$\begin{array}{l}\text { Total (stretched) length }(\mathrm{L}) \\
\text { from protein backbone to backbone } \\
\text { measured between the } \alpha \text {-carbons } \\
\text { of the amino acids, }(\AA)\end{array}$} \\
\hline & $\begin{array}{l}\text { Connecting } 2 \\
\text { Lys moieties } \\
\text { by their } \\
\varepsilon \text {-amines }\end{array}$ & $\begin{array}{l}\text { Connecting a } \\
\text { Lys } \varepsilon \text {-amine } \\
\text { and the amino } \\
\text { terminal }\end{array}$ \\
\hline 5 & 20.1 & 15.1 \\
\hline 6 & 21.4 & 16.3 \\
\hline 8 & $23.9^{1}$ & 18.8 \\
\hline 10 & 26.4 & 21.4 \\
\hline
\end{tabular}

acid and was spotted onto a stainless steel MALDI plate and then air dried. Samples for lower mass analysis $(0.8$ to $3 \mathrm{kDa})$ were prepared with a matrix of $\alpha$-cyano4-hydroxycinnamic acid and calibrated internally with ACTH clipped 18-39. Samples for higher mass analysis ( 3 to $20 \mathrm{kDa}$ ) were prepared with sinapinic acid matrix and calibrated internally with ACTH (18-39) and equine Cytochrome C. All samples were spotted in duplicate onto the plate. Mass spectra were acquired using a Bruker Reflex III MALDI-TOF MS (Bruker, Billerica, MA) in positive ion mode. The lower mass spectra were acquired by operating in reflectron mode in a mass-tocharge range of 0.8 to $3 \mathrm{kDa}$ with laser energy of $26 \%$. The higher mass spectra were acquired by operating in linear mode from 3 to $20 \mathrm{kDa}$ with laser energy of $29 \%$. In both cases, 300 scans were summed and then processed manually using XTOF software (Bruker). Mass error reporting limits were 50 and 100 ppm for masses below and above $3 \mathrm{kDa}$, respectively. Only peaks having a signal-to-noise ratio of at least 5 were used in the analysis.

The whole experiment was performed twice, and each time it was made in duplicate. Additionally, the final samples were spotted twice on the MALDI plate, and the mass spectrometry data acquisition was performed

Table 1. Details of crosslinkers (XL) used: molecular mass.

\begin{tabular}{llll}
\hline $\begin{array}{l}\text { Number of } \\
\text { carbons } \\
(n) \text { in } \\
\text { bridging } \\
\text { arm }\end{array}$ & XL name & $\begin{array}{l}\text { Molecular } \\
\text { mass }\end{array}$ & $\begin{array}{l}\text { Added molecular } \\
\text { mass during } \\
\text { crosslinking }\end{array}$ \\
\hline & & & $($ Da) \\
\hline 5 & bis(sulfosuccinimidyl) glutarate & 530.40 & 96.05 \\
6 & bis(sulfosuccinimidyl) adipate & 544.41 & 110.06 \\
8 & bis(sulfosuccinimidyl) suberate $\left(\mathrm{BS}^{3}\right)$ & 572.43 & 138.09 \\
10 & bis(sulfosuccinimidyl) sebacate & 600.45 & 166.11 \\
\hline
\end{tabular}

\footnotetext{
${ }^{1}$ The difference between the molecular mass of 2 singly crosslinked peptides, and the sum of molecular masses of these 2 peptides, uncrosslinked.
} 
separately on each of the 2 subsampled spots to maximize data collection.

Theoretical digestion and analysis of results. Primary sequences of $\beta-\mathrm{CN}$ (P02666) variants $\mathrm{A}^{1}$ and $\mathrm{A}^{2}$ (anticipating that both these common variants may be found in the $\beta$-CN sample that was purified from bulk milk from the university herd) were obtained from the Swiss-Prot Protein knowledgebase (The Swiss Institute of Bioinformatics, 2003). A theoretical digestion with each of the enzymes (trypsin and Glu-C) was carried out by the Web program MS-Digest (Baker and Clauser, 2002). Common isotopic masses were used for the calculations as well as in the mass spectrometry data analysis. Scanning for crosslinked peptide combinations and assigning them to matching masses were performed by an MS Excel-based application that we developed for this purpose. Only masses matching one possible interpretation of singly crosslinked peptide combinations were used in the analysis.

Intramolecular distance measurements in the model and plotting of the results were done based on the model coordinates (Kumosinski et al., 2003), using DS ViewerPro 5.0, Accelrys Inc. (Pharmacopeia Inc.).

\section{RESULTS AND DISCUSSION}

The concentration of $0.5 \mathrm{mg} / \mathrm{mL} \beta-\mathrm{CN}$ was chosen because it is the highest practical concentration before micellization of the casein commences (Schmidt and Payens, 1972; Niki et al., 1977; Evans et al., 1979). Micellization is undesirable in our experiments, as it would significantly increase the occurrence of intermolecular crosslinks. For the same reason, EDTA was used to prevent calcium-induced aggregation. This also allows a better comparison with the theoretical model (Kumosinski et al., 1993), which referred to an isolated state of the molecule. Still, some dimers may form by molecular collisions, necessitating the isolation of monomeric species before the digestion step. Figure 3 shows a typical SEC plot of the separation of the monomer from dimeric or oligomeric species that were present after the crosslinking reaction. This ensures that the crosslinked peptides following enzymatic digestion give information regarding intramolecular distances. Because the resolution of the chromatogram was not optimal and there was a region of overlap between the dimer and the monomer peaks, 3 fractions (labeled a, b, and c) were collected, as described in Figure 3, which shows a chromatogram obtained for a sample crosslinked with a C10 XL.

These 3 fractions were then concentrated and analyzed by PAGE. Figure 4 shows the results of this test for samples that were crosslinked with the 4 different $\mathrm{XL}$ used in this study. It can be seen that the fractions

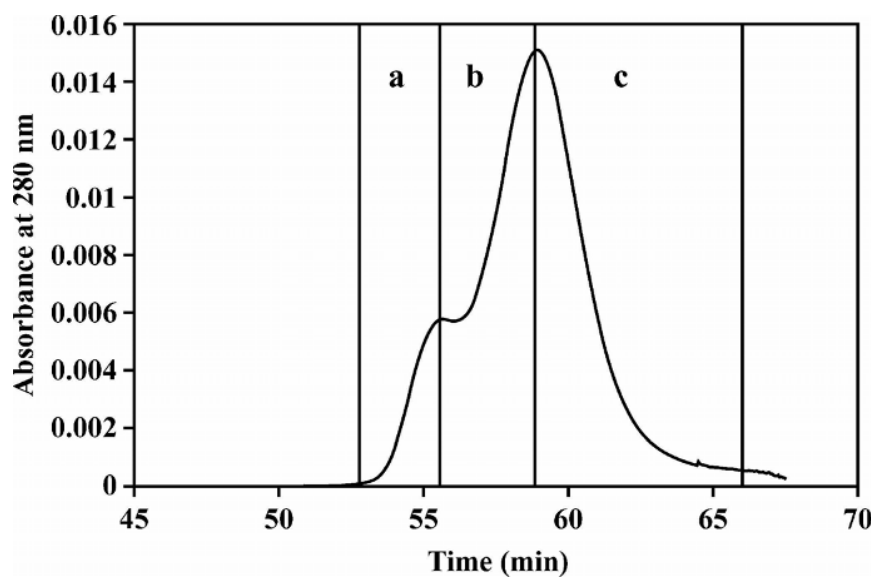

Figure 3. A typical size exclusion chromatography plot of the separation of monomeric (the peak with the longer elution time) from dimeric or oligomeric (shorter elution time) species after the crosslinking interaction. Collected fractions a, b, and c (see text) are delimited by vertical lines.

c from chromatography (lanes 4 and 7) contain only monomeric (M) protein (lanes 1 and 8 contain untreated $\beta$-CN as a reference), while the a-fractions contain mainly the dimeric (D) form, and some of the b-fractions contain both. In some of the samples, no dimer was found (e.g., the $\mathrm{C} 6$ sample). There seemed to be an increasing tendency to form dimers with the longer $\mathrm{XL}$ (C8 and C10), presumably because once a XL has attached to the protein with one end, the probability of another protein molecule coming within its reach increases with the XL length. A few c-fraction samples, which were found to contain a very small amount of dimer, were not analyzed further.

One preliminary question that we needed to answer before analyzing the crosslinks was the composition of genetic variants in the sample of $\beta$-CN used in our study, as the model, developed by Kumosinski et al. (1993), was based on the primary structure of the $\mathrm{A}^{2}$ variant, which is the most common in North American breeds. Together with the less common $\mathrm{A}^{1}$ variant, these 2 exceed $90 \%$ of the gene population (Swaisgood, 2003). By comparing our mass spectrometry results to theoretical digestion patterns of both these variants, we have mainly identified peptides common to both variants and peptides specific to $\mathrm{A}^{2} ; \mathrm{A}^{1}$-specific peptides were less prevalent. Among the peptides forming the crosslinks listed in Table 3 , none was $\mathrm{A}^{1}$-specific.

Table 3 lists the crosslinked peptides identified by analysis of the results of the MS data acquired from the various tryptic and Glu-C digests of the c-fractions from chromatography, which contained only monomeric species. Masses are reported only if they uniquely correspond to a singly charged $\left(\mathrm{M}+\mathrm{H}^{+}\right)$combination of 2 


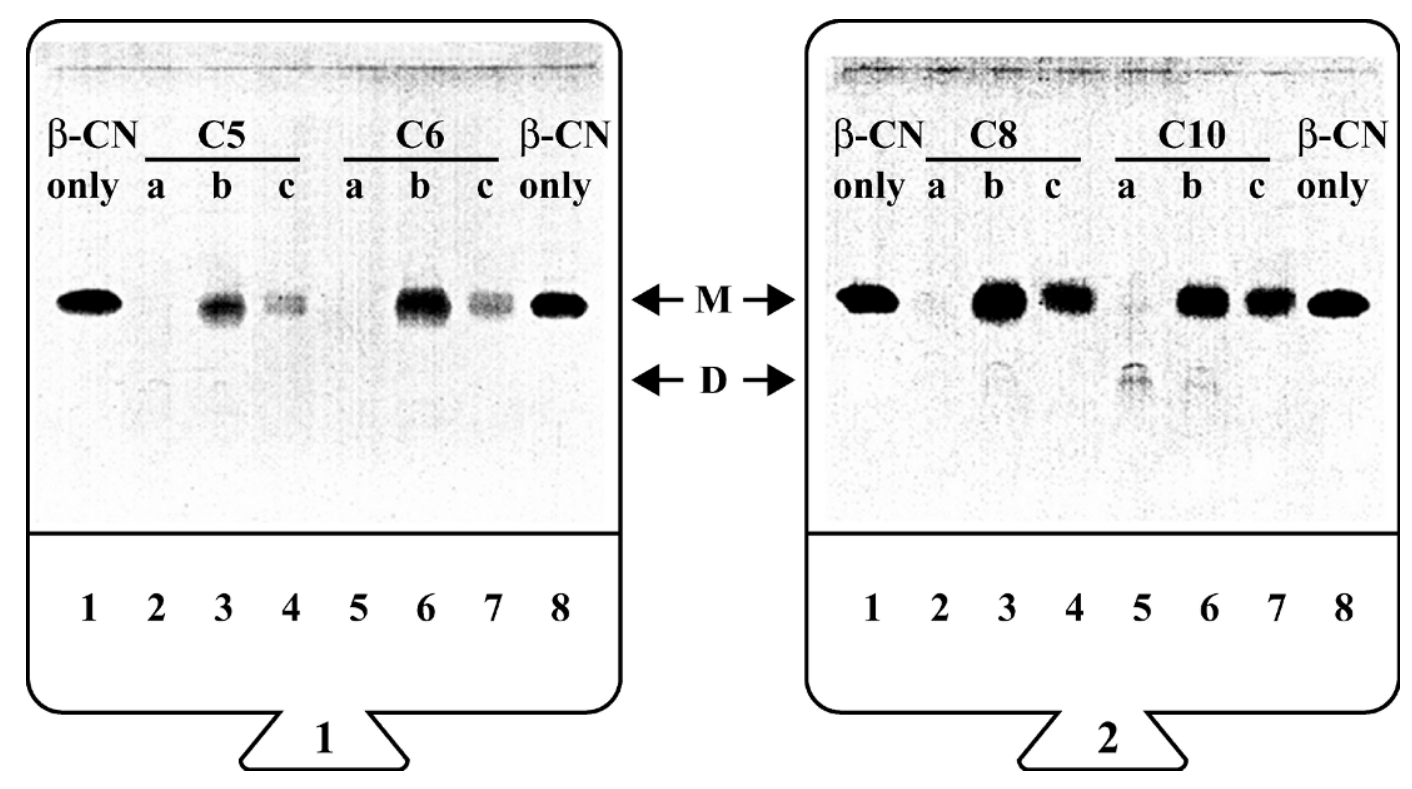

Figure 4. SDS-PAGE dimer test results of fractions collected during size exclusion chromatography. Lanes 1 and 8 are the reference untreated $\beta$-CN. Gel 1: lanes 2 to 4 and lanes 5 to 7 are C5 and C6 crosslinked $\beta$-CN samples, respectively. Gel 2 : lanes 2 to 4 and 5 to 7 are $\mathrm{C} 8$ and $\mathrm{C} 10$ crosslinked $\beta$-CN samples, respectively. Lanes 2 and 5, lanes 3 and 6 , and lanes 4 and 7 are fractions a, b, and c, respectively.

peptides and a crosslink, and where there is only one possible position of the crosslink. It is important to note that trypsin, which normally cleaves at the C-terminal side of lysine and arginine, cannot cleave on the Cterminal side of a crosslinked residue (Young et al., 2000). Several representative mass spectra are presented in Figure 5.

Table 3 shows that we were able to identify 10 masses that could be associated with the formation of crosslinks. However, these masses related to only 8 different crosslink positions, because 2 of the crosslink positions were identified by 2 masses each. For 2 of the crosslinks (K32-K113 and K48-K113), this is because the proteolysis was not complete so that the peptides on either side of the crosslink were not necessarily split at the closest cleavage site. Therefore, the peptides on each side of the crosslink could be of different masses, but the observation of both of them serves as a good confirmation of the crosslink identification in this position. In the case of the latter crosslink position (K48-K113), the 2 obser-

Table 3. Identified intramolecularly crosslinked peptide combinations.

\begin{tabular}{|c|c|c|c|c|c|c|c|}
\hline $\begin{array}{l}\text { Observed } \\
\mathrm{m} / \mathrm{z}(\mathrm{Da})\end{array}$ & $\begin{array}{l}\text { Matching } \\
\text { crosslinked } \\
\text { sequences }\end{array}$ & $\begin{array}{l}\text { Calculated } \\
\text { mass } \\
\mathrm{M}+\mathrm{H}^{+}\end{array}$ & & $\begin{array}{l}\text { Crosslinked } \\
\text { residues }\end{array}$ & $\begin{array}{l}\text { Distance } \\
\text { (D) by } \\
\text { model }^{1}\end{array}$ & $\begin{array}{l}\text { Length } \\
\text { (L) of } \\
\text { crosslink }\end{array}$ & $\begin{array}{l}\text { Difference }(d) \\
(d=L-D)\end{array}$ \\
\hline & & (Da) & & & $\longrightarrow$ & ) & \\
\hline $2232.1^{2}$ & $(1-5)-C 5-(32-42)^{3}$ & 2232.0 & & $\mathrm{R} 1^{4}-\mathrm{K} 32$ & 19.7 & 15.1 & -4.6 \\
\hline $2640.8^{2}$ & $(100-107)-C 8-(170-183)^{5}$ & 2640.6 & & K105-K176 & 40.6 & 23.9 & -16.7 \\
\hline $2793.3^{2}$ & $(32-43)-C 6-\left(109-117^{6}\right)^{3}$ & 2793.3 & 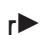 & K32-K113 & 21.4 & 21.4 & 0 \\
\hline $3807.7^{2}$ & $(1-11)-C 5-\left(109-129^{6}\right)^{3}$ & 3806.9 & & $\mathrm{R} 1^{4}-\mathrm{K} 113$ & 4.9 & 15.1 & 10.2 \\
\hline 4272.8 & $(1-25)-C 8-(106-113)^{5}$ & 4272.9 & & $\mathrm{R} 1^{4}-\mathrm{K} 107$ & 13.4 & 18.8 & 5.4 \\
\hline 4341.2 & $(32-43)-C 6-\left(109-131^{6}\right)^{3}$ & 4341.0 & 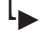 & K32-K113 & 21.4 & 21.4 & 0 \\
\hline 4879.1 & $(1-25)-C 10-(170-183)^{5}$ & 4879.4 & & $\mathrm{R} 1^{4}-\mathrm{K} 176$ & 25.7 & 21.4 & -4.3 \\
\hline 6521.5 & $\left(48-91^{6}\right)-\mathrm{C} 5-\left(109-121^{6}\right)^{3}$ & 6520.5 & 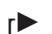 & K48-K113 & 22.2 & 20.1 & -2.1 \\
\hline 6667.5 & $\left(49-99^{6}\right)-C 6-(106-113)^{5}$ & 6666.6 & & K97-K107 & 9.6 & 21.4 & 11.8 \\
\hline 7662.9 & $\left(48-91^{6}\right)-C 10-\left(109-31^{6}\right)^{3}$ & 7664.1 & $\rightarrow$ & $\mathrm{K} 48-\mathrm{K} 113$ & 22.2 & 26.4 & 4.2 \\
\hline
\end{tabular}

\footnotetext{
${ }^{1}$ Kumosinski et al. (1993, 2003).

${ }^{2}$ See Figure 5.

${ }^{3}$ Identified in a glu-C digest.

${ }^{4}$ Amino-terminal connection.

${ }^{5}$ Identified in a tryptic digest.

${ }^{6} \mathrm{~A}$ variant $\mathrm{A}^{2}$-specific peptide.
} 
a.
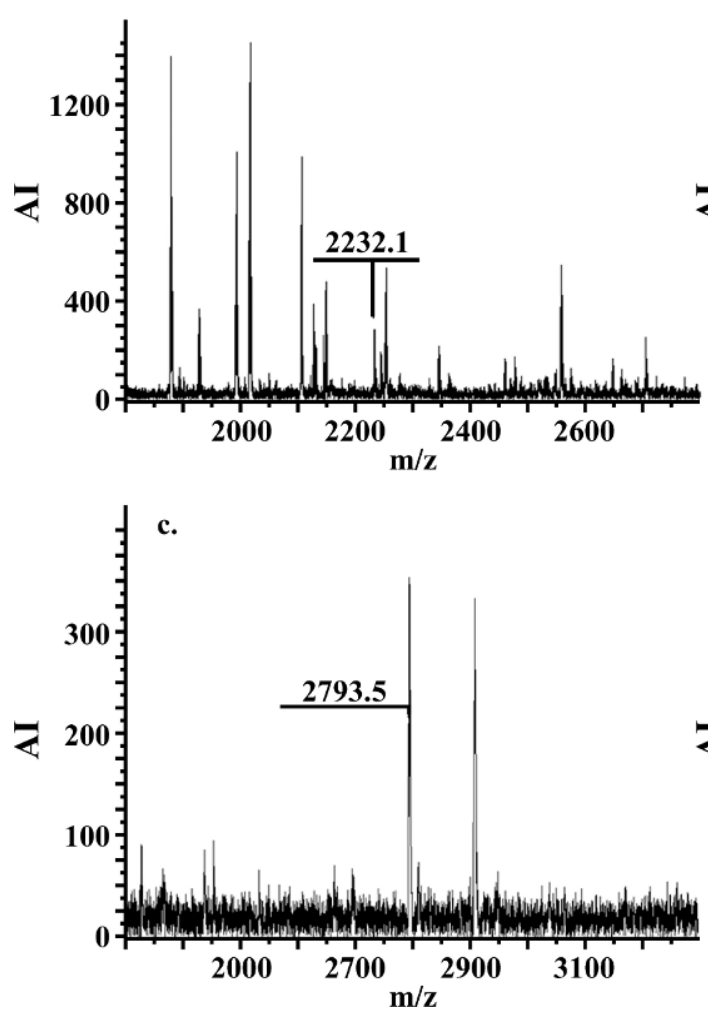

b.
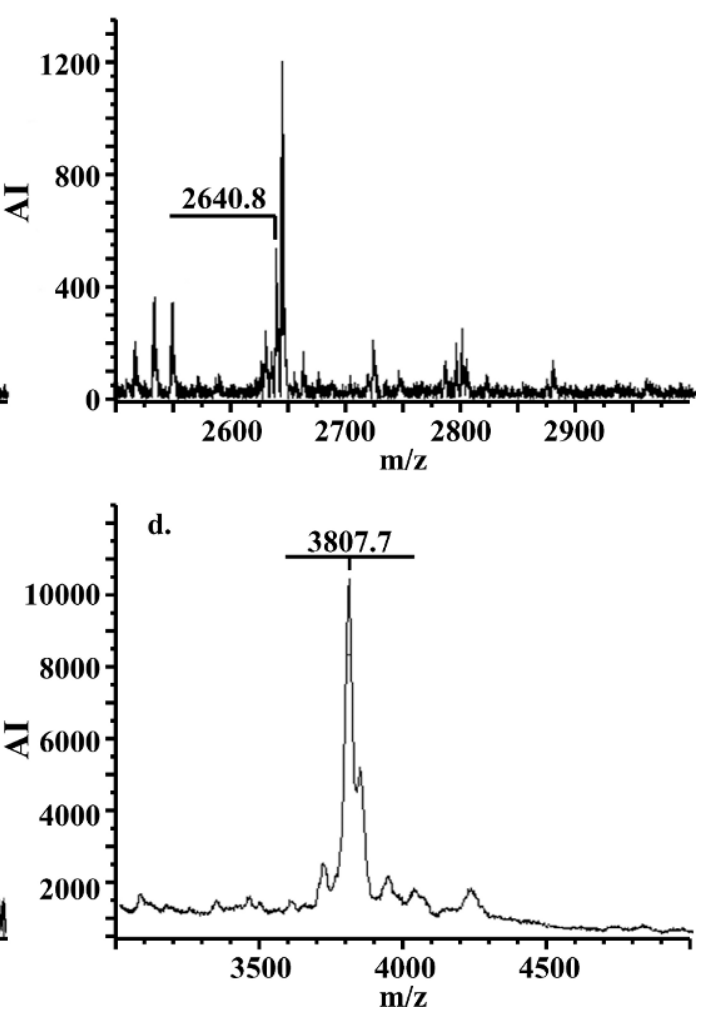

Figure 5. Examples of mass spectra obtained (see Table 3 for details). A) 2232.1, B) 2640.8, C) 2793.3, and D) 3807.7 . AI = measured intensity (arbitrary units).

vations differ also in the length of the XL arm, suggesting that at least the longer of the 2 (C10) was not fully stretched.

It is clear from Table 2 that we have identified only a few of the large number of potential crosslinks that are combinatorially possible between reactive amine groups in the protein. This can be taken as an indication that indeed selective reaction has occurred, governed by the lengths of the ligands, and that, therefore, the protein is not simply a highly mobile, disordered structure. Of the crosslinks identified, it is possibly relevant that 4 involve residue $\mathrm{R} 1$ and $4 \mathrm{~K} 113$ (one involves both); this may suggest that these residues are in positions in the molecule that are particularly available for reaction.

It might be interesting to note that although the digestion was done in an ammonium bicarbonate buffer, at $\mathrm{pH}$ of around 8 , we have observed a few aspartic acid cleavages by Glu-C, e.g., 2793.3 (Table 3 and Figure 5c) and 4341.2 , both containing peptide 32 to 43 (43 is Asp). Although it has been stated that this enzyme is specific for Glu-X bonds in presence of ammonium buffers (Houmard and Drapeau, 1972), others (Sorensen et al., 1991) showed evidence that ammonium bicarbonate does not improve the selectivity of Glu-C to Glu-X bonds, but only inhibits its overall activity. Moreover, compared with the conditions described by Drapeau (1977) and by Houmard and Drapeau (1972) (i.e., 50 to $100 \mathrm{~m} M$ ammonium bicarbonate, 1:30 enzyme:protein and 4 to $24 \mathrm{~h}, 37^{\circ} \mathrm{C}$ ), in the current study, the ammonium bicarbonate concentration was only $\sim 5 \mathrm{~m} M$, the enzyme to protein ratio was eventually $1: 10$, and the digestion time was $36 \mathrm{~h}$. Therefore, even less efficient cleavages apparently occurred to a significant extent.

The different crosslinks identified in Table 3 are shown in Figure 6, superimposed upon the tertiary structure model of $\beta$-CN developed by Kumosinski et al. (1993). Intramolecular distances between the $\alpha$-carbons of the bridged AA were calculated from the coordinates of the model (Kumosinski et al., 2003). Of the 8 different crosslinks identified in Table 3, 5 agree with the model within what we regard as a reasonable tolerance of -5 to $+10 \AA$ to allow for some molecular flexibility of the protein backbone and the long side groups of lysine residues, which may be pointing in different directions, as well as of the XL arm itself, which can bend but not stretch significantly. These crosslinks are labeled by thick solid lines in Figure 6 . The crosslink 


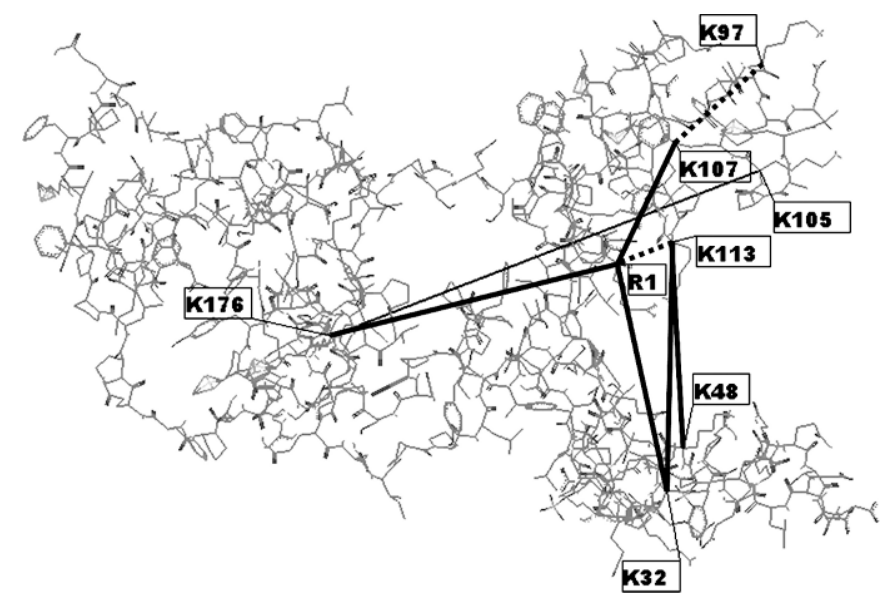

Figure 6. The locations of the identified crosslinks, listed in Table 3 , superimposed over the tertiary structure model of $\beta$-CN of Kumosinski et al. (1993; Kumosinski et al., 2003). A thick dotted line represents a crosslink too long compared with the model predicted distance $[\mathrm{d} \geq(+10 \AA)]$; a thick solid line represents crosslinks in agreement with the model $[(-5 \AA) \leq \mathrm{d}<(+10 \AA)]$; and a thin solid line represents a significant deviation from the model $[d<(-5 \AA)]$, where $d$ is the difference between the crosslink length (L) and the model distance (D) between the $\alpha$-carbons of the bridged amino acids $(\mathrm{d}=\mathrm{L}-\mathrm{D})$.

K32-K113, which was confirmed by 2 different masses, precisely fit $(\mathrm{d}=0)$ the model prediction of the distance between the 2 "arms" of the "crab-like" shape depicted by the model. In the case of K48-K113, the lengths of the 2 crosslinks observed bracketed the calculated distance from the model (Table 3).

Two other identified crosslinks, labeled by thick dotted lines in Figure 6, connect 2 residues that are much closer together (by $>10 \AA$ ) in the model than the maximum span of the crosslink. Because the XL arms are flexible, the calculated lengths (Table 3) can only give us limiting values for the distances. These links confirm the proximity of the linked residues, but lack more precise distance information and, therefore, can be regarded as generally supporting the model.

Only one of the crosslinks we identified (marked with a thin solid line in Figure 6) connected residues (K105K176) that, according to the model, are considerably farther apart from one another (40.6 $\AA$ ) than the stretched length of the crosslink (23.9 $\AA$ ). Thus, the model distance is about 1.7 times longer than the maximal "measured" distance in this case. Because we have taken every precaution to avoid the digestion of intermolecularly crosslinked protein molecules and the formation of spurious crosslinks arising from reactions during proteolysis, we believe that this crosslinked product can only come from the true formation of an intramolecular crosslink in the actual structure of the protein. Therefore, it appears that this crosslink is incompatible with the model, and it may suggest that the calculated structure needs to be somewhat compacted to allow better agreement with our measurements.

Overall, our results mainly support the model, predominantly regarding the $\mathrm{N}$-terminal moiety of the molecule (residues 1 to 113), in which the lengths of crosslinks identified agree in general with the predicted distances. Also in agreement was the crosslink from R1 to $\mathrm{K} 176$, measuring a distance to the $\mathrm{C}$-terminal region. It is unfortunate that the primary structure of the protein precludes observation of some parts of the structure (residues 49 to 96,114 to 168 , and 177 to 209), which have no anchoring points for the XL and, therefore, for which no information can be gained using the methods described here.

The apparent disparity between one of the crosslinks identified (K105-K176) and the predicted structure can possibly also be explained in terms of molecular flexibility. The model, which has been calculated to take into account allowable angles between adjacent amino acids, checked for agreement with measured secondary structure information and refined to minimize free energy, describes a probable conformation of this molecule. However, the presence of many prolines (17\% of the amino acids in its primary structure [Swaisgood, 2003]), introduces turns into the structure of $\beta$-CN that interrupt secondary structure sequences (e.g., $\alpha$-helices or $\beta$-sheets) and must result in an open (as opposed to a compact) tertiary structure (DeKruif and Holt, 2003). Such an open structure possesses greater conformational flexibility than compact globular proteins (DeKruif and Holt, 2003). This is enhanced by the lack in $\beta$ $\mathrm{CN}$ of intramolecular disulfide bonds, which often help to fix the tertiary folds of proteins. The tertiary structure of a flexible protein, such as a partly denatured protein in a molten globule state, may be found in one of several free-energy minima conformations, and the protein may interconvert between them (Jaenicke and Seckler, 1997; Qi et al., 2002). Caseins have been recently suggested to possess some characteristics of a molten globule (Farrell, Jr. et al., 2002); however, they have a more rigid and less compact structure than does a globular protein in a molten globule state (Horne, 2002; Syme et al., 2002). It is possible that the various crosslinks we have identified have not all occurred at a single fixed conformation (nor is it likely that many crosslinks occurred in a single protein molecule). An XL may bind at one end and remain loose at the other for some time (Figure 2) until the thermal molecular motion brings another reactive amino acid within its reach. This type of motion may possibly allow formation of such crosslinks as K105-K176, even if the conformation allowing them to form is not a very stable one.

Therefore, we conclude that while our results are mostly in agreement with the model of Kumosinski et 
al. (1993), the 3-D structure of $\beta$-CN is best described by the term rheomorphic (Holt and Sawyer, 1993). In other words, as was indicated by Kumosinski et al. (1993), it is not a fixed structure, as might be inferred from the static model, and on the other hand, it is not a random coil, as it is often referred to in the literature. Rather, it is a structure with several more definable and rigid parts, and others that are more flexible and dynamic, allowing the molecule to transform between several energetically favorable conformations under the influence of environmental forces, such as shear or thermal motion.

Following this conclusion, we should enter one caveat. The $\beta$-CN that we used was isolated from milk by a chromatographic method involving the use of $3.3 \mathrm{M}$ urea to dissociate the $\mathrm{CN}$ complexes. The urea was subsequently removed by dialysis. Urea, at high concentrations, is of course used as a denaturing agent for proteins, and most studies of $\beta$-CN in the literature involve this type of preparation. Therefore, it is conceivable that our results are derived from a protein that has a non-native structure. As far as we know, there is no evidence that $\beta$-CN prepared using urea is different from the protein in its native form or that isolated in other ways. Therefore, although our comments on the molecular flexibility are intended to refer to the native molecule as envisaged by Kumosinski et al. (1993), we can, in any case, be sure that they apply to the form of $\beta$-CN that has been most frequently used in laboratory studies of its physical chemistry.

\section{ACKNOWLEDGMENTS}

The authors thank the following individuals from the University of Guelph: Elizabeth Parker from the Department of Food Science for isolating the $\beta$-CN, Dyanne Brewer and Sibylle Heidelberger from the Department of Molecular Biology and Genetics for their invaluable professional assistance with mass spectrometry, and George Harauz from the Department of Molecular Biology and Genetics for his guidance on molecular imaging.

The work was supported financially by the Ontario Dairy Council and the Natural Sciences and Engineering Research Council of Canada.

\section{REFERENCES}

Andrews, A. T., D. Atkinson, M. T. A. Evans, E. G. Finer, J. P. Green, M. C. Phillips, and R. N. Robertson. 1979. The conformation and aggregation of bovine beta-casein A. I. Molecular aspects of thermal aggregation. Biopolymers 18:1105-1121.

Baker, P. K., and K. Clauser. 2002. ProteinProspector 4.04. Subject: MS-Digest. http://prospector.ucsf.edu/ucsfhtml4.0/msdigest. htm. Accessed Dec. 29, 2003.

Chang, R. 2002. Chemistry. 7th ed. McGraw-Hill, Boston, MA.
Dalgleish, D. G. 1993. The sizes and conformations of the proteins in adsorbed layers of individual caseins on latices and in oil-inwater emulsions. Colloids Surf. B Biointerfaces 1:1-8.

Dalgleish, D. G. 1997. Structure-function relationships of caseins. Pages 199-223 in Food Proteins and Their Applications. S. Damodaran and A. Paraf, ed. Marcel Dekker, Inc., New York, NY.

DeKruif, C. G., and C. Holt. 2003. Casein micelle structure, functions and interactions. Pages 233-276 in Advanced Dairy Chemistry1 Proteins Part A. 3rd ed. P. F. Fox and P. L. H. McSweeney, ed. Kluwer Academic/ Plenum Publishers, New York, NY.

Drapeau, G. R. 1977. Cleavage at glutamic acid with staphylococcal protease. Pages 189-191 in Enzyme Structure, Part E. Methods in Enzymology. Vol. 47. C. H. W. Hirs, S. Timasheff, and N. Timasheff, ed. Academic Press, New York, NY.

Evans, M. T. A., M. Phillips, and M. N. Jones. 1979. The conformation and aggregation of bovine $\beta$-casein A. II. Thermodynamics of thermal association and the effects of changes in polar and apolar interactions on micellization. Biopolymers 18:1123-1140.

Farrell, H. M., Jr., E. M. Brown, and T. F. Kumosinski. 1990. Bovine caseins: Three-dimensional molecular modeling. Proc. 23rd Int. Dairy Congr., Montreal, Quebec, Canada 2:1526-1533.

Farrell, H. M., Jr., P. X. Qi, E. M. Brown, P. H. Cooke, M. H. Tunick, E. D. Wickham, and J. J. Unruh. 2002. Molten globule structures in milk proteins: Implications for potential new structure-function relationships. J. Dairy Sci. 85:459-471.

Farrell, H. M., Jr., E. D. Wickham, J. J. Unruh, P. X. Qi, and P. D. Hoagland. 2001. Secondary structural studies of bovine caseins: Temperature dependence of $\beta$-casein structure as analyzed by circular dichroism and FTIR spectroscopy and correlation with micellization. Food Hydrocoll. 15:341-354.

Hollar, C. M., A. J. R. Law, D. G. Dalgleish, and R. J. Brown. 1991. Separation of major casein fractions using cation-exchange fast protein liquid chromatography. J. Dairy Sci. 74:2403-2409.

Holt, C., and L. Sawyer. 1993. Caseins as rheomorphic proteins: Interpretation of primary and secondary structures of the $\alpha_{\mathrm{S1}^{-}}$, $\beta$ - and $\kappa$-caseins. J. Chem. Soc. Faraday Trans. 89:2683-2692.

Horne, D. S. 2002. Casein structure, self-assembly and gelation. Curr. Opin. Colloid Interface Sci. 7:456-461.

Houmard, J., and G. R. Drapeau. 1972. Staphylococcal protease: A proteolytic enzyme specific for glutamoyl bonds. Proc. Natl. Acad. Sci. USA 69:3506-3509.

Jaenicke, R., and R. Seckler. 1997. Protein misassembly in vitro. Adv. Protein Chem. 50(10):1-59.

Kajiwara, K., R. Niki, H. Urakawa, Y. Hiragi, N. Donkai, and M. Nagura. 1988. Micellar structure of $\beta$-casein observed by smallangle x-ray scattering. Biochim. Biophys. Acta 955:128-134.

Kumosinski, T. F., E. M. Brown, and H. M. Farrell, Jr. 1993. Threedimensional molecular modeling of bovine caseins: An energyminimized $\beta$-casein structure. J. Dairy Sci. 76:931-945.

Kumosinski, T. F., E. M. Brown, and H. M. Farrell, Jr. Agriculture Research Service, Eastern Regional Research Center (ARSERRC). 2003. Subject: Casein protein structures. http:// www.arserrc.gov/dpp/casein.htm. Accessed Jun. 10, 2003.

Niki, V. R., K. Takase, and S. Arima. 1977. [On the shape and size of temperature-dependent $\beta$-casein aggregates.] Milchwissenschaft 32:577-582. (In German).

Qi, P. X., E. M. Brown, and H. M. Farrell, Jr. 2002. 'New views' on structure-function relationships in milk proteins. Trends Food Sci. Technol. 12:339-346.

Ribadeau-Dumas, B., G. Brignon, F. Grosclaude, and J. C. Mercier. 1972. [Primary structure of bovine beta casein. Complete sequence.] Eur. J. Biochem. 25:505-514. (In French).

Schmidt, D. G., and T. A. J. Payens. 1972. Evaluation of positive and negative contributions to the second virial coefficient of some milk proteins. J. Colloid Interface Sci. 39:655-662.

Scholnick, F., L. L. Liao, E. M. Brown, and S. H. Feairheller. 1992. Crosslinking of collagen with dicarboxylic acids. J. Am. Leather Chem. Assoc. 87:333-338.

Sinz, A. 2003. Chemical cross-linking and mass spectrometry for mapping three-dimensional structures of proteins and protein complexes. J. Mass Spectrom. 38:1225-1237. 
Sorensen, S. B., T. L. Sorensen, and K. Breddam. 1991. Fragmentation of proteins by S. aureus strain V8 protease. Ammonium bicarbonate strongly inhibits the enzyme but does not improve the selectivity for glutamic acid. FEBS Lett. 294:195-197.

Staros, J. V. 1982. N-hydroxysulfosuccinimide active esters: bis(Nhydroxysulfosuccinimide) esters of two dicarboxylic acids are hydrophilic, membrane-impermeant, protein cross-linkers. Biochemistry 21:3950-3955.

Swaisgood, H. E. 2003. Chemistry of the caseins. Pages 139-202 in Advanced Dairy Chemistry-1 Proteins Part A. 3rd ed. P. F. Fox and P. L. H. McSweeney, ed. Kluwer Academic/ Plenum Publishers, New York, NY.

Syme, C. D., E. W. Blanch, C. Holt, R. Jakes, M. Goedert, L. Hecht, and L. D. Barron. 2002. A Raman optical activity study of rheomorphism in caseins, synucleins and tau. New insight into the structure and behavior of natively unfolded proteins. Eur. J. Biochem. 269:148-156.

Tanford, C. 1972. Micelle shape and size. J. Phys. Chem. 76:30203024.

The Swiss Institute of Bioinformatics. S. I. B. ExPASy (Expert Protein Analysis System) proteomics server. 2003. Subject: Swiss-Prot protein knowledgebase. http://us.expasy.org/sprot/sprottop.html. Accessed Dec. 29, 2003.

Thurn, A., W. Burchard, and R. Niki. 1987. Structure of casein micelles. I. Small-angle neutron scattering and light scattering from $\beta$ - and $\kappa$-casein. Colloid Polym. Sci. 265:653-666.

Young, M. M., N. Tang, J. C. Hempel, C. M. Oshiro, E. W. Taylor, I. D. Kuntz, B. W. Gibson, and G. Dollinger. 2000. High throughput protein fold identification by using experimental constraints derived from intramolecular cross-links and mass spectrometry. Proc. Natl. Acad. Sci. USA 97:5802-5806. 